\title{
Time Course and Time-Distance Relationships for Surround Suppression in Macaque V1 Neurons
}

\author{
Wyeth Bair, ${ }^{1,2}$ James R. Cavanaugh, ${ }^{2}$ and J. Anthony Movshon ${ }^{1,2}$ \\ ${ }^{1}$ Howard Hughes Medical Institute and ${ }^{2}$ Center for Neural Science, New York University, New York, New York 10003
}

Iso-orientation surround suppression is a powerful form of visual contextual modulation in which a stimulus of the preferred orientation of a neuron placed outside the classical receptive field (CRF) of the neuron suppresses the response to stimuli within the CRF. This suppression is most often attributed to orientation-tuned signals that propagate laterally across the cortex, activating local inhibition. By studying the temporal properties of surround suppression, we have uncovered characteristics that challenge standard notions of surround suppression. We found that the latency of suppression depended on its strength. Across cells, strong suppression arrived on average $30 \mathrm{msec}$ earlier than weak suppression, and suppression sometimes arrived faster than the excitatory CRF response. We compared the relative latency of CRF response onset and offset with the relative latency of suppression onset and offset. Response onset was delayed relative to response offset in the CRF but not in the surround. This is not the expected result if neurons targeted by suppression are like those that generate it. We examined the time course of suppression as a function of distance of the surround stimulus from the CRF and found that suppression was predominantly sustained for nearby stimuli and predominantly transient for distant stimuli. By comparing the latency of suppression for nearby and distant stimuli, we found that orientation-tuned suppression could effectively propagate across $6-8 \mathrm{~mm}$ of cortex at $\sim 1 \mathrm{~m} / \mathrm{sec}$. This is considerably faster than expected for horizontal cortical connections previously implicated in surround suppression. We offer refinements to circuits for surround suppression that account for these results and describe how feedback from cells with large CRFs can account for the rapid propagation of suppression within V1.

Key words: macaque monkey; primary visual cortex; surround suppression; contextual modulation; response latency; propagation velocity; cortical feedback

\section{Introduction}

Receptive fields of neurons in the visual cortex can be decomposed into a classical receptive field (CRF), in which stimuli directly elicit a neuronal response, and an area beyond the CRF, in which stimuli elicit no response of their own but can profoundly modulate a CRF-driven response (for review, see Allman et al., 1985; Gilbert, 1992; Fitzpatrick, 2000; Albright and Stoner, 2002). Understanding the mechanisms underlying contextual modulation from the field surrounding the CRF is therefore critical to understanding how the visual system processes arbitrary patterns and natural scenes (Vinje and Gallant, 2000). Most studies of contextual modulation have focused on spatial structure and stimulus selectivity of the surround field, whereas little attention has been given to the temporal profile of the modulation. However, the time course of contextual signals is important because it can constrain both the underlying circuitry and the functional role of contextual modulation (Knierim and Van Essen, 1992; Lamme, 1995; Lee et al., 1998).

Received March 4, 2003; revised June 23, 2003; accepted June 30, 2003.

This work was supported by National Institutes of Health Grant EY02017. J.R.C. was supported by a National Science Foundation predoctoral fellowship. We thank Matthew A. Smith and Adam Kohn for assistance with data collection, helpful discussion, and comments on this manuscript.

Correspondence should be addressed to Wyeth Bair, Howard Hughes Medical Institute, Center for Neural Science, New York University, 4 Washington Place, Room 809, New York, NY 10003. E-mail: wyeth@ens.nyu.edu.

J. R. Cavanaugh's present address: National Eye Institute, Bethesda, MD 20892.

Copyright $\odot 2003$ Society for Neuroscience $\quad$ 0270-6474/03/237690-12\$15.00/0
Here we study the time course of orientation-tuned surround suppression (Blakemore and Tobin, 1972; Fries et al., 1977; Nelson and Frost, 1978; Allman et al., 1985; DeAngelis et al., 1994; Anderson et al., 2001), a prominent form of contextual modulation in the primary visual cortex (Hubel and Wiesel, 1968; De Valois et al., 1985; Knierim and Van Essen, 1992; Sillito et al., 1995; Nothdurft et al., 1999; Levitt and Lund, 2002). It is widely believed that the extensive horizontal axonal projections within V1, particularly in layers 2 and 3, offer a conduit for surround suppression (Gilbert and Wiesel, 1983; Allman et al., 1985; Gilbert and Wiesel, 1990; Born and Tootell, 1991; Hirsch and Gilbert, 1991; McGuire et al., 1991; Gilbert, 1992; Knierim and Van Essen, 1992; DeAngelis et al., 1994; Grinvald et al., 1994; Toth et al., 1996; Nothdurft et al., 1999; Dragoi and Sur, 2000; Fitzpatrick, 2000; Anderson et al., 2001; Hupé et al., 2001b; Stettler et al., 2002). Alternatively, studies of surround suppression in the context of texture pop-out and figure-ground segregation (Knierim and Van Essen, 1992; Lamme, 1995; Zipser et al., 1996) found that surround modulation was delayed relative to CRFdriven responses and suggested that the delay was consistent with feedback. However, horizontal propagation within V1 is probably slow (Grinvald et al., 1994; Nowak and Bullier, 1997; Bringuier et al., 1999; Girard et al., 2001; Slovin et al., 2002), whereas connections between V1 and higher cortical areas can be fast (Movshon and Newsome, 1996; Nowak and Bullier, 1997; Girard et al., 2001; Hupé et al., 2001a). Therefore, a delay in the arrival of 


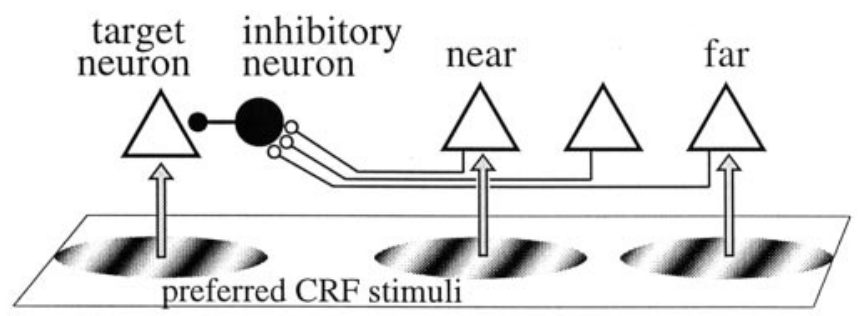

Figure 1. Putative circuit for iso-orientation surround suppression in V1. The target neuron (left triangle) receives inhibition from a nearby neuron (large filled circle) that is driven by excitatory neurons displaced laterally in cortex ( 3 triangles at right) that have orientation tuning similar to the target cell. Preferred stimuli confined to the CRFs for three excitatory neurons are indicated by the circular patches of sinusoidal grating shown on the tilted plane that represents a two-dimensional visual field. Arrows emanating from the stimuli indicate localized feedforward inputs to the excitatory neurons. We find that this circuit is insufficient to account for some temporal features of surround suppression.

suppression cannot discriminate feedback from horizontal propagation.

To further resolve mechanisms of surround suppression, we considered the implications of a simple circuit (Fig. 1) for the timing of suppression. Here, an orientation-tuned target neuron (triangle at left) is suppressed by an inhibitory neuron (black circle) that is driven by similarly tuned neurons displaced laterally in the cortex (triangles at right). We examined two aspects of timing for this circuit. First, we compared the timing of response onsets and offsets for CRF stimuli with that for surround stimuli. We recently reported that response onset latency was consistently longer than offset latency (in $>95 \%$ of cells and by $10-20 \mathrm{msec}$ on average) for cortical neurons driven by dynamic CRF stimuli (Bair et al., 2002). If suppression originates from neurons having an onset delay, the onset of suppression should be delayed relative to its offset. Second, we examined the relationship between the onset time of suppression and the distance of the surround stimulus from the CRF. If suppression travels via slow, horizontal propagation from similarly tuned cells in other cortical columns, then the latency of suppression should increase for more distant surround stimuli in a manner that reflects the propagation speed of the horizontal fibers.

\section{Materials and Methods}

Electrophysiology. We recorded extracellularly from primary visual cortex of anesthetized, paralyzed macaque monkeys (two Macaca nemestrina and eight $M$. fascicularis). Detailed methods for this type of recording are available in an article by Levitt et al. (1994). Experiments typically lasted 4-5 d, during which anesthesia and paralysis were maintained with sufentanil citrate $\left(4-6 \mu \mathrm{g} \cdot \mathrm{kg}^{-1} \cdot \mathrm{hr}^{-1}\right)$ and vecuronium bromide (Norcuron, $0.1 \mathrm{mg} \cdot \mathrm{kg}^{-1} \cdot \mathrm{hr}^{-1}$ ), respectively, administered in lactated Ringer's solution $\left(8 \mathrm{ml} \cdot \mathrm{kg}^{-1} \cdot \mathrm{hr}^{-1}\right)$ containing dextrose $(2.5 \%)$. Artificial respiration with a mixture of $\mathrm{O}_{2}, \mathrm{~N}_{2} \mathrm{O}$, and $\mathrm{CO}_{2}$ was maintained with rate adjustments to keep expired $\mathrm{CO}_{2}$ between 3.8 and $4.0 \%$. Body temperature was maintained near $37^{\circ} \mathrm{C}$ with a heating pad. Electroencephalograms and electrocardiograms were monitored to ensure proper depth of anesthesia. All procedures conformed to guidelines of the New York University Animal Welfare Committee.

Tungsten-in-glass microelectrodes (Merrill and Ainsworth, 1972) were advanced with a hydraulic microdrive downward through a craniotomy of 9-10 $\mathrm{mm}$ in diameter centered typically $4 \mathrm{~mm}$ posterior to the lunate sulcus and $10 \mathrm{~mm}$ lateral to the midline. In some experiments, we used a mechanical microdrive system with quartz-platinum/tungsten microelectrodes (Thomas Recordings, Marburg, Germany). Action potentials were discriminated using a hardware dual-window time-amplitude discriminator (Bak) and time-stamped at a resolution of $0.25 \mathrm{msec}$. Electrolytic lesions $2 \mu \mathrm{A}$ for $2-5$ sec were made for histological verifica- tion and estimation of the cortical layer. Neurons were recorded both on the operculum and in the calcarine sulcus [typical receptive field (RF) eccentricities were $1-6$ and $8-20^{\circ}$, respectively].

At the end of experiments, animals were perfused with $4 \%$ paraformaldehyde in saline. Cortical sections of $40 \mu \mathrm{m}$ were mounted on slides and stained for Nissl substance with cresyl violet. We reconstructed electrode tracks by locating the electrolytic lesions and by visualizing tissue damage from the passage of the electrode. We determined the laminar location of each cell on the basis of visual inspection of landmarks in the stained sections, as described by Cavanaugh et al. (2002).

Visual stimuli. Visual stimuli were generated by custom software on a Cambridge Research Systems (Kent, UK) 2/2 board and presented on a standard cathode ray tube (CRT) at $100 \mathrm{~Hz}$ vertical refresh with mean luminance of $33 \mathrm{~cd} / \mathrm{m}^{2}$. The CRT was placed farther from the monkey's eye for smaller RFs and closer for larger RFs (range, $80-180 \mathrm{~cm}$ ). For each cell whose action potential waveform was well isolated from the noise, we systematically optimized the orientation, spatial period, and temporal frequency of a sine wave grating at 100\% contrast that drifted for 2-4 sec behind a circular aperture chosen to approximate the CRF. We then used the smallest patch of optimal grating that provided a reliable response to find the center of the RF. Next, we presented stimuli in an interleaved manner consisting of either a single circular patch of variable diameter or a single annular patch of variable inner diameter For annuli, the outer diameter was set to the maximum extent of our screen, which ranged from 10 to $20^{\circ}$ of visual angle, depending on the screen placement. We defined the CRF region to be the smallest circular patch that produced at least $95 \%$ of the maximum response (for a detailed description, see Cavanaugh et al., 2002, where this region is referred to as the "grating summation field"). We defined the surround region to be the annulus with the minimum inner diameter that evoked no response above the spontaneous level. Across the database, the ratio of surround inner diameter to CRF size had a mean of 0.19 , a median of 0.16 , and a mode of $0.15(n=92)$.

Our dynamic center-surround stimulus consisted of two patches of drifting grating that were presented in the CRF and surround apertures defined above. The stimulus consisted of a random sequence of states (Fig. 2C) in which each grating drifted in either the preferred direction or in an orthogonal direction for one full cycle of sinusoidal modulation. At the end of each state, each grating was randomly and independently assigned to have either the preferred or orthogonal direction for the next state. Thus, at each state boundary (i.e., after each full cycle of drift), each grating either drifted seamlessly or made a $90^{\circ}$ change in orientation and direction. Opportunities for state transitions occurred simultaneously for the CRF and surround. The two possible directions of motion for the CRF and surround created four possible states and 16 state transitions, which occurred at random. The state transitions of interest for this study are labeled above the icons in Figure 2C. When describing states and state transitions, we will refer to orientation and direction as "preferred" when they are the same as those preferred by the CRF, even when referring to stimuli that are located in the surround. Likewise, "orthogonal" always means at $90^{\circ}$ to preferred. Thus, a stimulus in the surround that has the orientation preferred by the CRF is called preferred even though it is a suppressive stimulus.

The dynamic stimulus was presented in trials lasting $30 \mathrm{sec}$ and was interleaved with a center-alone and a surround-alone control in which the contrast of the grating in the other aperture was set to zero. There were $4 \mathrm{sec}$ of mean gray between trials. If the surround-alone stimulus yielded a substantial response to the transition from orthogonal to preferred, the inner diameter of the annulus was increased to eliminate the response. The temporal frequency of the grating was sometimes increased from the optimum (if the optimum was $<4 \mathrm{~Hz}$ and if doing so did not cause the firing rate to drop to $<90 \%$ of optimal) because this increased the number of times that each state transition was tested. We used temporal frequencies ranging from 3.1 to $25 \mathrm{~Hz}$, but most cells were tested at either 6.25 or $12.5 \mathrm{~Hz}$. The spatial phase of the surround grating was set to match that of the center grating. In two cells, we varied the phase of the surround grating and found that it did not affect our results. This is consistent with reports that surround suppression is primarily phase-insensitive (Nelson and Frost, 1978; DeAngelis et al., 1994). 
To test the dependence of surround suppression on the distance of the surround stimulus from the CRF, we designed a second, simpler experiment that allowed us to focus on the timing of the onset of suppression. In this experiment, the optimal drifting grating for the CRF appeared on a mean gray background for $1 \mathrm{sec}$, and a surround stimulus appeared 400 msec later and lasted for $300 \mathrm{msec}$. Six stimuli were interleaved in a block-wise random manner with 2 sec of mean gray between stimuli. Five of the six stimuli had surrounds, which extended from the outer border of our screen to an inner diameter that varied across stimuli, and the sixth stimulus had no surround. This allowed us to study the time course of suppression for stimuli at various distances from the CRF with reference to the time course of the response to the CRF stimulus when no surround stimulus was imposed.

Data analysis. The response to a particular transition of the dynamic stimulus was computed by averaging together segments of spike trains (1 msec resolution) shortly before and after each occurrence of the transition. The spike trains were aligned to the time of the state transition before averaging, and the resulting average is referred to as a peristimulus time histogram (PSTH). PSTHs were filtered in time with a Gaussian of an $\mathrm{SD}$ of $2 \mathrm{msec}$ and plotted in units of spikes per second. Responses to the stimuli in which a surround was flashed on were computed in a similar manner, with the onset of the stimulus taken as the temporal reference.

We computed the latency of response to a change in the visual stimulus (e.g., a state transition or the appearance of a surround stimulus) by first subtracting the reference response (the PSTH in response to no change in the stimulus) from the response PSTH for the change. We then identified the maximum of the absolute value of this response difference, and we searched backward in time from the maximum to the point at which the difference was equal to $5 \%$ of the maximum. The time of this point was defined as the response latency. Thus, latencies were the times of $5 \%$ rise to the peak response difference. This is the same method that we used previously (Bair et al., 2002).

We compared our method with one that chooses the latency to be the point at which the response difference reaches a criterion statistical significance. Because the latter requires the response to reach a fixed level, the latency estimate will grow as the change in response is scaled down. This is undesirable because later we show that, on average, the strength of suppression is approximately scaled down for far surround stimuli (see Results). We tested both latency methods on PSTHs for simulated Poisson spike trains in which the firing rate changed at a fixed time from an initial level to a final level in $20 \mathrm{msec}$ (which was typical for our data). As expected, the $5 \%$ latency method was substantially less dependent on the final rate than was the statistical criterion method for both rate increases and decreases. For changes in the rate approximating the smallest in our data, even the 5\% latency method began to show an increased bias (up to $4 \mathrm{msec}$ longer than the true latency). However, such small rate changes occurred only for the most distant surround stimuli, for which the bias operates in a conservative manner with respect to our conclusions (see Discussion).

We computed the suppression strength, $1-r s / r p$, for responses to the dynamic center-surround stimulus from the firing rate $(r p)$ during the preferred stimulus (preferred CRF, orthogonal surround) and the rate during suppression ( $r$; preferred CRF, preferred surround; recall that, in the surround, the orientation preferred by the CRF is typically the most suppressive). Firing rates were computed in a time window equal to one period (drift cycle) of the stimulus. This window was centered in an epoch twice as long, which corresponded to two consecutive periods of the pertinent stimulus. This ensured that the response was measured in an epoch that began after the signals arrived in the cortex (i.e., it accounted for the visual latency).

The spontaneous firing rate was computed in $500 \mathrm{msec}$ epochs preceding the onset of each trial of the dynamic center-surround stimulus.

We computed a cortical magnification factor (CMF) using the same equation that we used previously (Cavanaugh et al., 2002):

$$
\mathrm{CMF}^{-1}= \begin{cases}0.15 E, & E<1^{\circ} \\ 0.15 E+0.076 E, & 1^{\circ} \leq E \leq 4^{\circ} \\ 0.086 E, & E \geq 4^{\circ},\end{cases}
$$

where $E$ is the receptive field eccentricity in degrees (Van Essen et al., 1984; Tootell et al., 1988).

\section{Results}

\section{Temporal characteristics of surround suppression}

By definition, stimuli outside the CRF do not elicit responses; therefore, we used stimuli in the CRF to evoke responses that the surround could modulate. We chose drifting (rather than static) sinusoidal gratings because they maximized the sustained portion of the CRF-evoked response. This worked well for complex cells, which have relatively unmodulated responses to drifting gratings. Simple cells, however, responded with strong modulation at the fundamental temporal frequency, obscuring the temporal profile of surround suppression and preventing the measurement of response latencies. Therefore, we present results for complex cells only. There is strong evidence that surround suppression operates similarly for simple and complex cells (Dreher, 1972; Rose, 1977; Kato et al., 1978; Nelson and Frost, 1978; Walker et al., 2000; Mizobe et al., 2001; Cavanaugh et al., 2002; Levitt and Lund, 2002).

We studied surround suppression in 92 orientation-tuned complex cells. A typical orientation tuning curve is shown for an example neuron in Figure $2 A$, where vertically and horizontally oriented icons depict the preferred and orthogonal stimuli, respectively. After quantitatively optimizing the orientation, direction, and spatial and temporal frequencies of a circular patch of drifting grating, we varied the diameter of the optimal patch to compile a size tuning curve. The example neuron had an optimal diameter of $\sim 1^{\circ}$ of visual angle (Fig. $2 B$, filled circles, small icon). We defined the CRF region to be the disk of optimal diameter. Stimuli larger than the CRF yielded smaller, suppressed responses. Cells for which the largest grating gave the maximum response were considered unsuppressed and were not among the 92 studied here. The CRF size ranged from 0.35 to $3.1^{\circ}$ (mean, $1.0^{\circ}$ ) for cells $1-6^{\circ}$ eccentric and from 0.72 to $4.2^{\circ}$ (mean, $1.9^{\circ}$ ) for cells $>8^{\circ}$ eccentric. To define a region that lay outside the CRF, we presented the optimal grating in annuli of various inner diameters (the outer diameter was set to the maximum extent of our screen). The annulus tuning curve (Fig. 2B, open circles) shows that the response dropped to zero as the inner diameter of the annulus pulled away from the center of the CRF. We initially defined the surround region (Fig. $2 \mathrm{~B}$, large icon) to be the annulus of smallest inner diameter that elicited a response no greater than the spontaneous rate ( 0 spikes/sec for this example cell). In cases in which there was a gray region between the surround and CRF stimuli, we tested intermediate inner diameters to verify that the surround stimulus was as close as possible to the CRF without eliciting a significant excitatory response.

Within the CRF and surround regions, we presented a random, dynamic stimulus that consisted of a grating drifting at either the preferred orientation or the orientation orthogonal to preferred. We will refer to these orientations as preferred and orthogonal regardless of whether they occurred in the CRF or surround. Figure $2 C$ shows a sample stimulus sequence for six periods of the dynamic center-surround stimulus. The stimulus icons show the CRF and surround orientation in each period, which lasted for the time that it took the gratings to drift one spatial cycle (typically $160 \mathrm{msec}$; range, $80-320 \mathrm{msec}$ ). At the end of the period, each grating was randomly and independently assigned either the preferred or orthogonal orientation for the next period. Thus, at each period boundary, a grating either drifted seamlessly or made an abrupt $90^{\circ}$ orientation shift. For example, at the first transition in Figure $2 C$, the CRF stimulus changed from orthogonal to preferred (i.e., horizontal to vertical), whereas the surround stimulus remained orthogonal. This tran- 

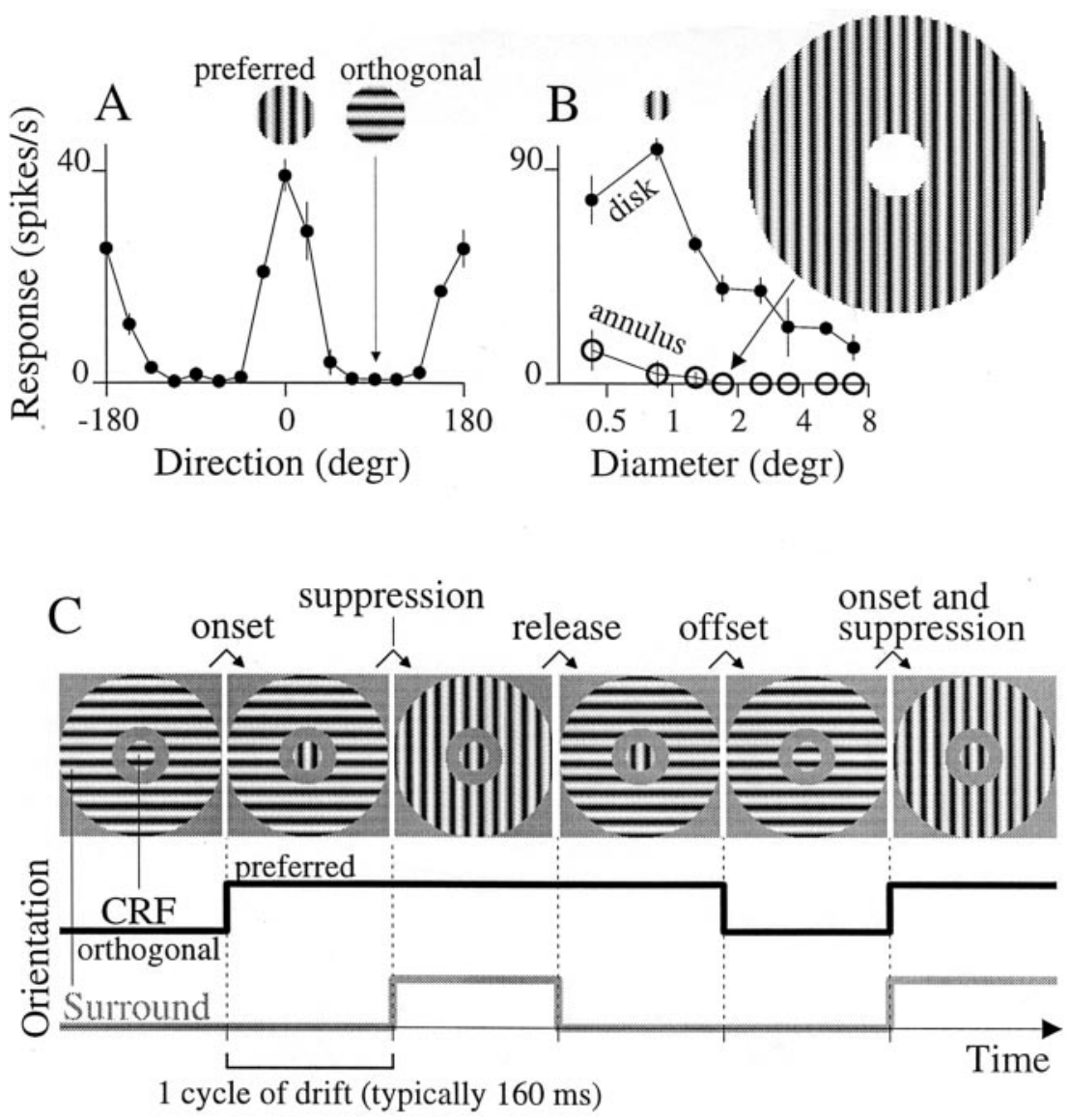

Figure 2. Tuning curves for orientation and size were used to configure our dynamic center-surround stimulus. $A$, The mean firing rate of an example neuron ( 3 trials, 4 sec/trial) is plotted against the drift direction (in degrees, relative to preferred) of a sinusoidal grating. Motion was always orthogonal to the orientation of the grating; therefore, we refer to this as an orientation tuning curve. Error bars indicate SEM. The stimulus of preferred orientation is shown by the icon above the peak at zero. The spontaneous rate for this neuron was zero. $B$, A size tuning curve (filled circles) shows mean response versus stimulus diameter for the same neuron. The optimal size (small icon) was smaller than that in $A$, which accounts for larger responses here. The annulus tuning curve (open circles) shows the response to gratings presented in an annular window versus the inner diameter of the annulus. The outer diameter was set to fill our screen. The CRF region (small icon) was the disk that optimized the size tuning curve. The surround region (large icon) was the annulus with the smallest inner diameter that did not elicit a response above the spontaneous firing rate. The arrow marks the inner diameter for the surround region. Icons here and in $A$ are drawn to scale. C, The icons depict a succession of six states of the dynamic center-surround stimulus (see Materials and Methods). The gratings in the (RF (center disk) and surround (annulus) drifted in either the preferred direction (shown as vertical) or in an orthogonal direction (horizontal). For clarity, the surround annulus outer diameter is shown here at $50 \%$ of the size determined in B. Below the icons, orientation is plotted versus time for the CRF (black line) and surround (gray line). The state transitions of interest here are labeled above the bent arrows. This sequence was chosen for convenient demonstration; the actual sequence of transitions was random.

sition, labeled onset, usually provoked a strong CRF-driven excitatory response. At the next transition, suppression, the surround changed to the preferred orientation. This configuration usually maximized surround suppression. The suppression is released at the next transition (release), when the surround changes back to orthogonal. At the fourth transition (offset), the CRF stimulus changed from preferred to orthogonal. The final transition shown in Figure 2 involves a simultaneous change in the CRF and surround stimuli that sets the excitation of the preferred CRF stimulus against the suppression of the surround. During the actual stimulus, these five state transitions occurred at random and among the 16 possibilities (see Materials and Methods).

Our first goal was to assess whether the timing of response onsets and offsets driven by the CRF and surround were consistent with the circuit in Figure 1. To do this, we focus on the responses to the five stimulus transitions just described. Figure 3 shows the responses for the example cell, which was typical of the population. The onset of the preferred CRF stimulus (Fig. 3A, change between left, right icons) caused a sudden increase in mean firing rate (black line) $52 \mathrm{msec}$ after the stimulus transition $(t=0)$. The response curve was computed by averaging together the spike trains surrounding all occurrences (here, 119) of this stimulus transition. Also shown is the reference curve (gray line), which is the average response for two periods of the stimulus depicted by the left icon (i.e., orthogonal orientation is maintained in CRF and surround). We defined the response latency to be the time at which the response diverged from the reference curve by a criterion amount (see Materials and Methods), which is indicated by the distance between the pair of dots beneath the arrow (see Fig. $3 A$ legend). For the opposite stimulus transition, i.e., a change from preferred to orthogonal in the CRF, a decrease in the rate ensued (Fig. 3B, black line). The reference curve (gray line) shows the response to the maintained preferred stimulus. For clarity, the change in response (response minus reference) is plotted in the gray inset. The offset latency $(29 \mathrm{msec})$ was $\sim 23$ msec shorter than the onset latency, consistent with our previous findings (Bair et al., 2002).

The time course for surround suppression is shown in Figure 3C, where only the surround stimulus changed. The latency of suppression (indicated by the arrow) was larger than both the onset and offset latencies for the CRF. However, the suppression was nearly absolute, and its onset was as abrupt as the rate changes elicited via the CRF. The release of suppression (Fig. 3D) was not as abrupt, but it occurred with a latency similar to that of suppression. The data in Figure 3, $A$ and $C$, imply that the suppressive signal from the surround took longer to affect the spike rate than did the CRF excitation. A compelling demonstration of this is provided by the response to the simultaneous change of the CRF and surround from the orthogonal to the preferred orientation (Fig. 3E). The response to this simultaneous transition (thick black line) followed the response for CRF onset alone (gray dashed line, replotted from Fig. $3 A$ ) for $\sim 20 \mathrm{msec}$ (during the period between the vertical dotted lines). Thereafter, the response was suppressed with a time course consistent with the suppression observed in Figure $3 C$ (replotted in Fig. $3 E$ as the black dashed line).

For each orientation-tuned complex cell that had orientationtuned suppression, we measured the latencies for the stimulus transitions described in Figure 3A-D. Their distributions are plotted in Figure 4. The histograms for the CRF (Fig. $4 A, B$ ) show that the mean offset latency was shorter than the mean onset latency (arrows show means). When offset latency was plotted against onset latency for each cell, nearly all of the points fell below the diagonal (Fig. $4 E$ ), indicating that stimulus offset con- 


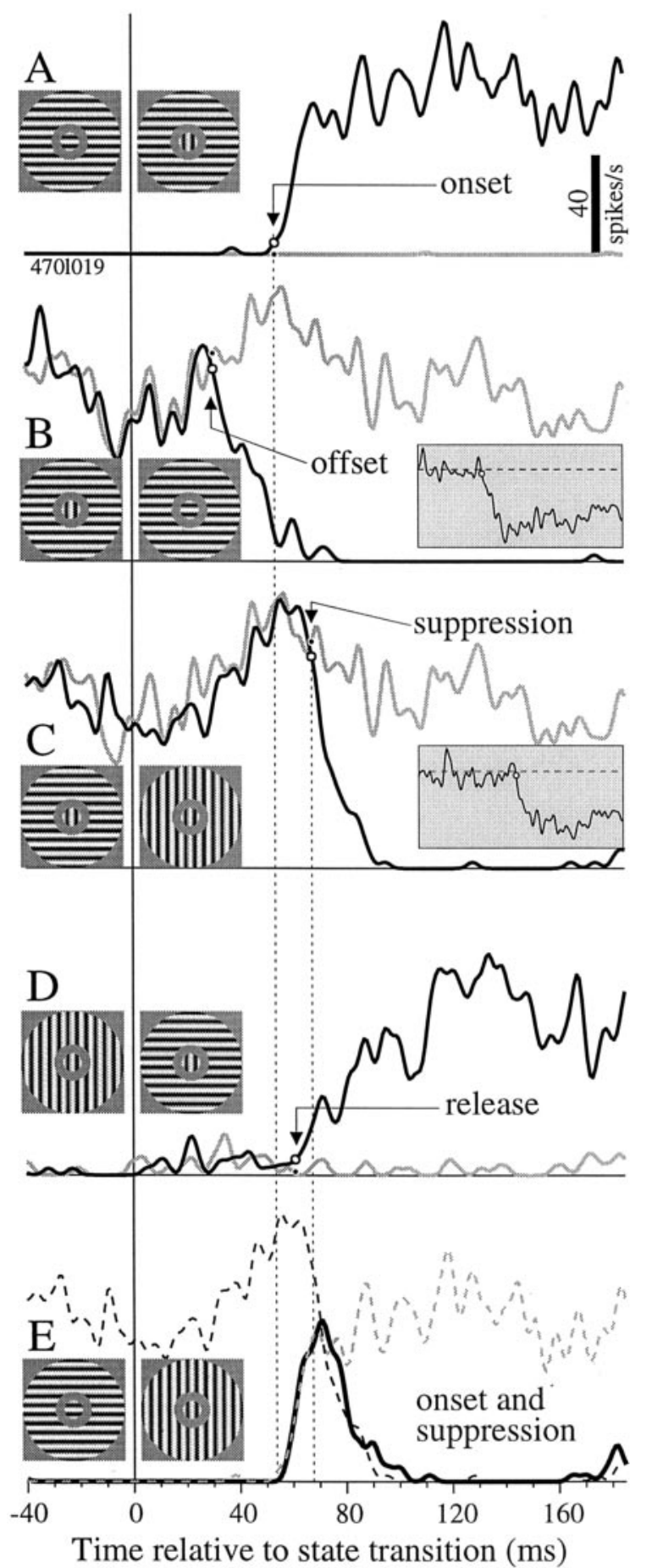

Figure 3. The dynamic center-surround stimulus elicited rapid increases and decreases in firing rate via the $C R F$ and the surround. In each plot, the black trace shows the mean firing rate (calibration in $A$ ) versus time for the stimulus transition indicated by the pair of icons. The icons straddle $t=0$, the time of the stimulus transition. $A-D$, Reference curves (gray lines) show the response to two consecutive periods of the stimulus indicated by the left icon. All curves are averages over $100-120$ repeats (see Materials and Methods). $A$, The response increased when the CRF stimulus changed from orthogonal (shown as horizontal in icons) to preferred (vertical) but the surround orientation stayed orthogonal (nonsuppressive). The reference response, $\sim 0$ spikes/sec, lies on the $x$-axis. The arrow labeled onset points to an open circle on the response curve (black line) and shows the response latency, which is defined as the time of $5 \%$ rise to the maximum difference between the response and the reference curves (see Materials and Methods). The distance from the open circle to the black dot (on the reference curve) indicates the $5 \%$ response difference. The onset time is also marked by a vertical dotted line for comparison with plots below. $B$, The response decreased when the CRF stimulus changed from preferred to orthogonal (with orthogonal surround). This response offset began earlier (arrow) than the
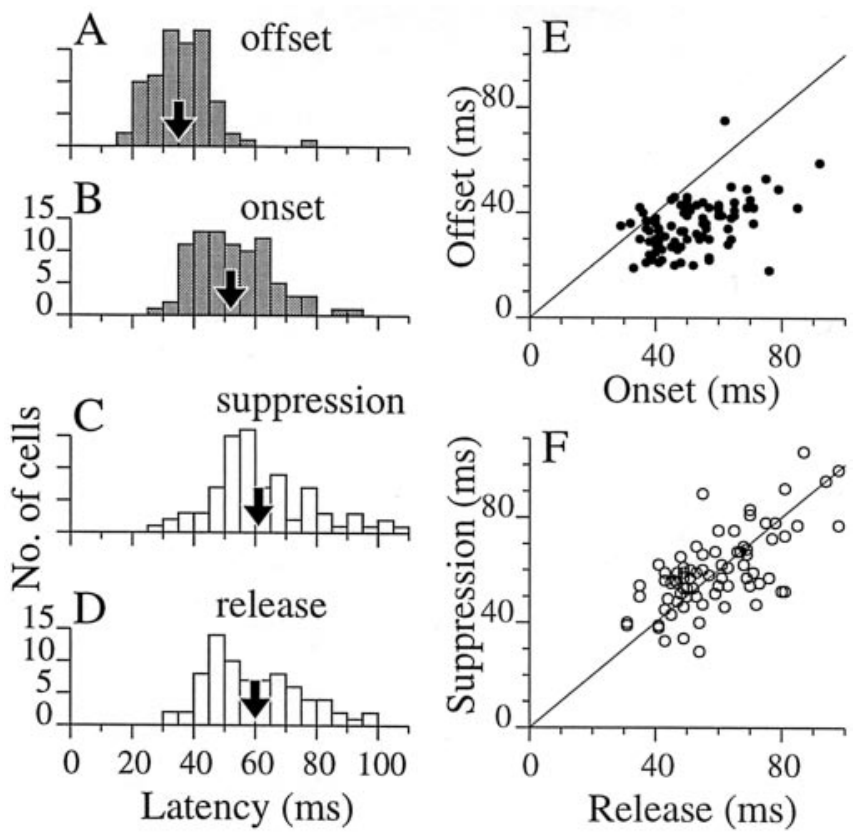

Figure 4. Comparison of response timing for CRF and surround signals across cells. $A-D$, The distribution of response latencies (see Materials and Methods) for CRF transitions (gray histograms) and surround transitions (open histograms) are plotted for 92 cells (arrows show means). On average, (RF offset ( $A$ ) was earliest ( $35 \mathrm{msec} ; \mathrm{SD}, 10 \mathrm{msec}$ ). (RF onset ( $B$ ) occurred on average $17 \mathrm{msec}$ later ( $52 \mathrm{msec} ; \mathrm{SD}, 13 \mathrm{msec}$ ). Surround modulation occurred the latest on average [61 and $60 \mathrm{msec}$ for suppression ( $C$ ) and release $(D)$, respectively; $S D, 17 \mathrm{msec}$. E, For each neuron, offset time is plotted against onset time. Almost all points fall below the unity diagonal, indicating that almost all cells responded to the offset faster than to the onset of the preferred stimulus in the CRF. Offset latency also was significantly less variable than onset latency (SD, 9.7 and $13 \mathrm{msec} ;$; test, $p=0.009$ ). F, For the surround, suppression time is plotted against release time. These values were on average not different across cells (paired $t$ test, $p=$ $0.87 ; n=85)$ and were significantly correlated $\left(r=0.70 ; p<10^{-6}\right)$.

sistently affected neuronal output more rapidly than stimulus onset. This temporal asymmetry, or onset delay, is characteristic of signals driven by changes between preferred and antipreferred stimuli in the CRF (Bair et al., 2002). However, the same comparison for the surround (Fig. 4C,D) indicates that suppressive modulation showed no such asymmetry in timing; the points in Figure $4 F$ cluster around the diagonal. This outcome is somewhat surprising in the context of the circuit for surround suppression shown in Figure 1. If cells driving the surround signal have an onset delay, then suppression, which is caused by response onset in the surround, should have a longer latency than release of suppression, which is caused by offsets in the surround. The naive prediction that suppression onset is slower than its release is not borne out in Figure 4F. If this simple circuit is fundamental to surround suppression, how can we explain the lack of onset delay for suppression? Keeping the assumption that signals arriving at

$\leftarrow$

response onset in $A$. The inset shows the difference between the response and reference curves, where the dashed line is 0 difference, and the circle marks $5 \%$ of the maximum difference. C, The response to the preferred CRF stimulus was suppressed by a transition of the surround from orthogonal to preferred. The decrease was at least as rapid as that for CRF offset in $B$. Suppression latency (arrow) is indicated by a vertical dotted line. The inset shows the difference, as in B.D, The release of suppression, caused by the surround changing to orthogonal with the CRF stimulus remaining preferred, occurred at about the same time (arrow) as suppression in C.E, A simultaneous change in the center and the surround caused a response (thick line) that followed the CRF onset response (gray dashed line, replotted from A) until approximately the time of suppression (right vertical dotted line). Thereafter, the response followed the time course of suppression (black dashed line, replotted from C). 

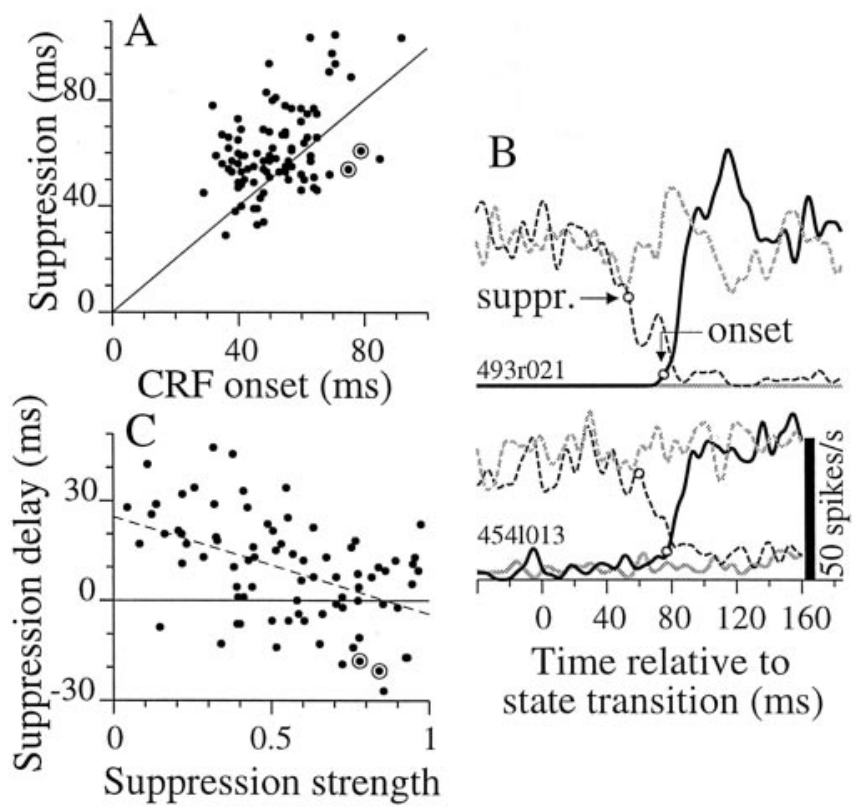

Figure 5. Latency of suppression relative to CRF onset. $A$, Suppression latency is plotted against CRF onset latency for 87 cells. In most cells, suppression arrived later than CRF excitation, but in some (points below diagonal line), suppression arrived sooner. $B$, For two example cells ( $A, C$, circled points) for which suppression came before onset, response curves are shown for suppression (suppr.; dashed lines) and onset (solid lines). Solid lines show response (black) and reference (gray) curves for the transition like that of Fig. $3 A$. Dashed lines show the response (black) and reference (gray) curves for the transition like that of Fig. 3C. Open circles mark 5\% latencies, as in $A$ and C. C, For each cell, suppression delay (suppression latency minus CRF onset latency) is plotted against suppression strength ( 1 indicates complete suppression; 0 , no suppression). There is a significant negative correlation between suppression delay and strength ( $r=-0.48 ; p<10^{-5} ; n=87$ ). Strong suppression often occurred as early as (RF onset, whereas weak suppression was delayed by $\sim 30 \mathrm{msec}$ on average. The dashed line shows a linear regression.

the inhibitory neuron (Fig. 1, black circle) have an onset delay, one possible solution is that the inhibitory relay somehow delays the release, but not the onset, of suppression. In Discussion, we describe how such a delay could occur if the effect of inhibition on the target neuron persists for 10-20 msec after the inhibitory neuron stops firing.

The second prominent feature of the latency histograms is that suppression is delayed on average relative to CRF onset (Fig. 4 , compare $B, C$ ). The average delay, $9 \mathrm{msec}(\mathrm{SD}, 15 \mathrm{msec}$ ), was shorter than the 15-20 msec range reported by previous studies (Knierim and Van Essen, 1992; Nothdurft et al., 1999). Those studies, however, used sparse fields of short bars, which may be a weaker stimulus for surround suppression, and they relied on averages across populations of cells. Our data allowed a cell-bycell examination of the delay and its relationship to other parameters, so we will briefly describe several major trends and some of their implications.

Plotting suppression latency versus CRF onset latency (Fig. $5 A$ ) shows that suppression occurred later than CRF onset for most cells, but that for some cells (points below the diagonal), suppression began before the CRF response. Examples of responses for two such cells (Fig. $5 A$, circled points) are shown in Figure $5 B$, where the divergence of the solid black and gray lines shows the time of onset (same format as Fig. $3 A$ ), and the divergence of the dashed black and gray lines shows the time of suppression (similar to Fig. 3C). In both examples, suppression starts $\sim 20 \mathrm{msec}$ before onset. This predicts a range of behavior for suppressed cells when preferred orientation is presented simultaneously in the CRF and surround. Some cells should fire briefly before being suppressed (as in Fig. $3 E$ ), whereas others should be suppressed early and may not respond at all if suppression is strong. This range of behavior is what we observed across neuronal responses (data not shown) to stimulus transitions such as that depicted in Figure 3E.

Figure $5 \mathrm{~A}$ also reveals a positive correlation between suppression and onset latencies $(r=0.44 ; p<0.0001 ; n=87)$, indicating that, on average, cells responding early to CRF stimulation also received suppression early. If CRF and surround signals operated through primarily independent mechanisms and if suppression entailed extensive pooling, one might expect the timing of these signals to be uncorrelated. Perhaps the observed correlation is caused by some delaying operation that acts downstream from the point where CRF and surround signals are combined. This is possible if the two signals are combined early in a subset of cells whose outputs incur delays along their paths to drive other cells downstream within V1.

An unexpected relationship was revealed when suppression delay (suppression latency minus CRF onset latency) was plotted against suppression strength (Fig. $5 C$ ). Suppression delay was inversely correlated with suppression strength across cells $(r=$ $-0.48 ; p<0.0001 ; n=87)$. The delay was on average $\sim 30 \mathrm{msec}$ longer for weak suppression than for strong suppression. This relationship was supported by weaker correlations (data not shown) between suppression strength and the two components of suppression delay: suppression strength was correlated positively with CRF onset latency $(r=0.20 ; p=0.05)$ and negatively with suppression latency $(r=-0.34 ; p=0.001)$. Thus, cells with stronger suppression responded sooner to surround suppression and later to CRF excitation compared with cells with weaker suppression on average. We also found that suppression strength was inversely correlated with the spontaneous firing rate $(r=$ $-0.37 ; p=0.0006 ; n=82$; correlation against $\log$ of spontaneous rate). Perhaps one factor, variation in the strength of inhibitory input across cells, is responsible for all of these correlations. For example, if the target cell in Figure 1 received more (or stronger) inhibitory synapses, it might suppress faster when those synapses were activated and might have a lower spontaneous rate because of greater tonic inhibition. The slower CRF onset could be caused by the CRF stimulus partially activating the strong inhibitory surround or could result from greater tonic inhibition.

However, an important possibility to consider is that the negative correlation between suppression strength and suppression latency could be caused by variations in our choice of the inner diameter for the surround stimulus. For surround stimuli placed farther from the CRF, we expect suppression to be weaker (Jones, 1970; Nothdurft et al., 1999; Levitt and Lund, 2002). If suppression from more distant stimuli also takes longer to arrive, as expected for the horizontal propagation model shown in Figure 1 , then a negative correlation between strength and latency would ensue. The results of the next section show that such an explanation is unlikely to account for our data.

\section{Time course as a function of distance}

An important yet untested prediction of the circuit in Figure 1, in which surround suppression arises via horizontal propagation of signals from cells with similar tuning in nearby columns of visual cortex, is that the distance traveled should be related to the time of arrival of suppression. To test for such a relationship, we measured the time course of suppression for surround stimuli at various distances from the CRF in 31 cells. We presented sur- 

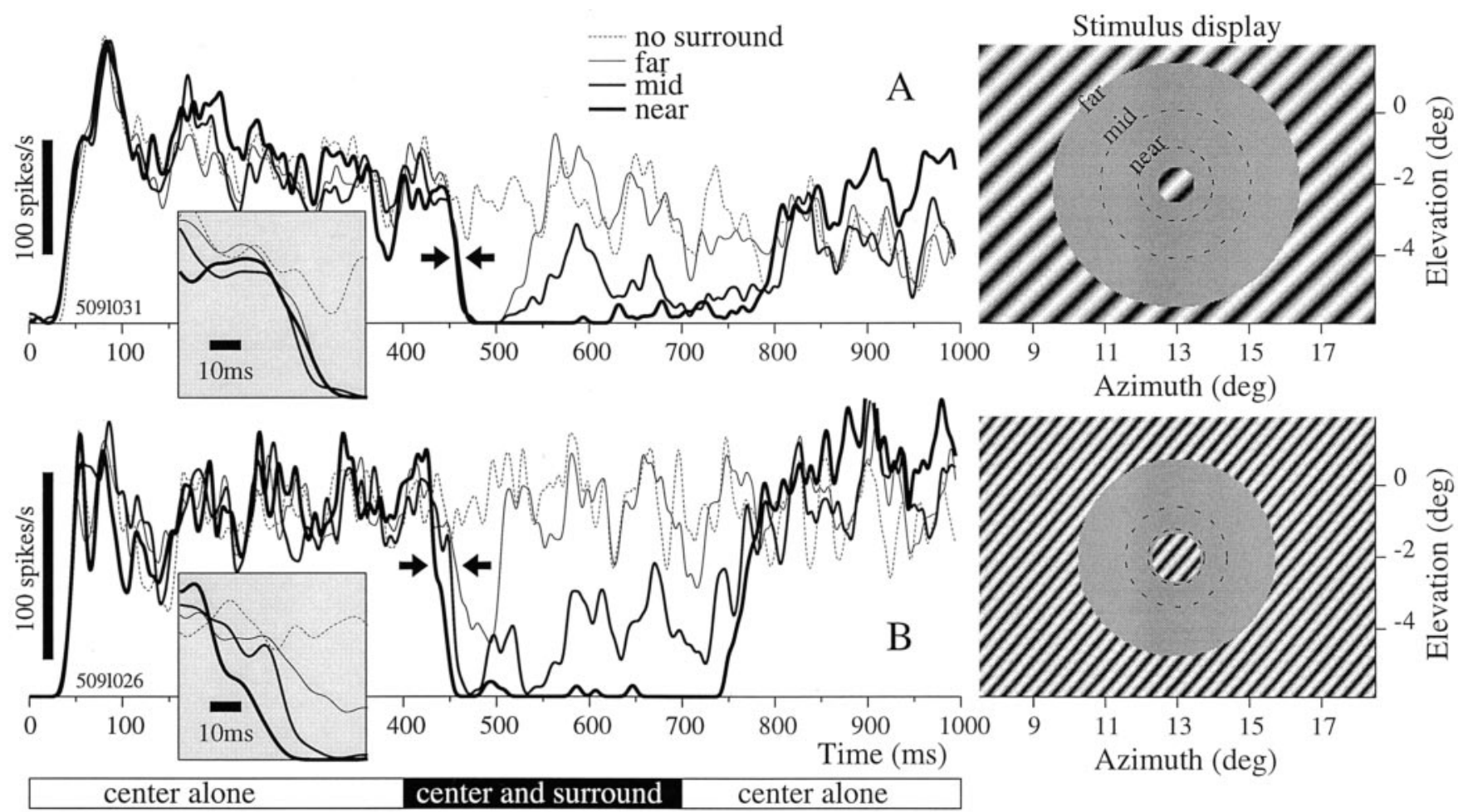

Figure 6. The time course of suppression is shown for surround stimuli that lie at several distances from the CRF for two example neurons. A, The stimulus display (right) shows the CRF stimulus, which was a central patch of grating optimized for the CRF, and the far surround stimulus, which was a grating extending from the edges of the display to a circular inner border. The dashed circles mark inner borders for two other surround stimuli: the mid and near surrounds. The CRF stimulus appeared for 1 sec starting at $t=0$, and the surround stimulus appeared for $300 \mathrm{msec}$ starting at $t=400 \mathrm{msec}$ (timing bar at bottom). The preferred orientation and spatial frequency were as shown. The mean firing rates ( $n=20$ trials, convolved with Gaussian; SD, 4 msec) are shown for the near, mid, and far surrounds (thick to thin lines). The response to the CRF stimulus alone is shown by the dotted line. The near surround strongly suppressed the response to the CRF (thickest black line; arrows indicate onset of suppression). The suppression caused by the mid surround initially had a time course similar to that of the far surround but became weaker after $\sim 50 \mathrm{msec}$. The far surround suppression (thin solid line) was strikingly transient but did not deviate substantially in the first $50 \mathrm{msec}$ from the near surround suppression. The square gray inset shows a blowup of the curves around the time of suppression onset. For this cell, the onset of near suppression occurred at $65 \mathrm{msec}$ compared with $48 \mathrm{msec}$ for the onset of the CRF response. $B$, Data for a second example neuron are formatted as in $A$. Averages are of 30 trials. As in $A$, the suppression became more transient as the surround withdrew from the CRF, but unlike the previous example, the latency of suppression consistently increased as the surround withdrew. The onset of near suppression occurred at $46 \mathrm{msec}$, which was earlier than the onset of the CRF response at $50 \mathrm{msec}$.

round stimuli for $300 \mathrm{msec}$ during an ongoing optimized CRF stimulus. We used brief stimuli to maximize the number of repeated trials and thereby increase the accuracy of our timing estimates. Figure $6 \mathrm{~A}$, right panel, depicts the stimulus at an instant when the surround was present. The surround grating extended from the outer edge of the video display to an inner circular border that was concentric with the circular CRF stimulus in the center of the display. The diagram shows the far surround stimulus (that most remote from the CRF), whereas the two dashed circles mark the inner borders for a mid surround (at an intermediate distance) and the near surround (that closest to the CRF).

Responses to four stimulus conditions are shown in Figure $6 \mathrm{~A}$ for one example neuron. The dashed line shows the response to the CRF stimulus presented alone, and the three solid lines, from thick to thin, show the responses to near, mid, and far surround stimuli, respectively. The thick line shows that the firing rate of this cell was strongly suppressed during a period of $\sim 300 \mathrm{msec}$ that corresponded to the epoch when the near surround was present (allowing for $50 \mathrm{msec}$ response latency). For surrounds that were farther away (thinner lines), the suppression was weaker on average during the $300 \mathrm{msec}$ interval. However, the onset of suppression occurred at approximately the same time (arrows; inset shows blowup), and the suppression was initially strong $(100 \%)$ for all surrounds. Figure $6 B$ shows results for a second example neuron that displayed a systematic change in suppression latency with distance of the surround (curves be- tween arrows; inset shows blowup). For this cell, suppression from more distant surrounds arrived later. Like the first example cell, suppression was weaker and displayed a strong transient component for more distant surrounds.

For each complex cell, we computed the change in suppression onset time, $\Delta t$, associated with the change from the near to far surround. In particular, $\Delta t$ was the onset latency for far suppression minus that for near suppression, where onset latency was defined as the time at which suppression reached $5 \%$ of its maximum value (see Materials and Methods). We also estimated the associated change in distance, $\Delta x$, that the signals would have to travel if they propagated laterally within V1. We multiplied the distance between the inner borders of the near and far surrounds (i.e., the number of degrees of visual angle that the surround receded) by the cortical magnification factor (Van Essen et al., 1984; Tootell et al., 1988) that was appropriate for the eccentricity of the receptive field (see Materials and Methods, Eq. 1). Figure $7 A$ shows these values for all 31 neurons tested. The two circled points show values for the example cells of Figure 6 . The point for Figure $6 A, \Delta x=2.15 \mathrm{~mm}$ and $\Delta t=1 \mathrm{msec}$, fell near the vertical line at $\Delta t=0$, indicating that suppression from the far surround required little or no additional time to arrive compared with suppression from the near surround. For the example cell of Figure $6 B, \Delta x=1.84 \mathrm{~mm}$, and $\Delta t=22 \mathrm{msec}$. The effective propagation speed in this case is just under $0.1 \mathrm{~m} / \mathrm{sec}$, which is indicated by the dashed line of the shallowest slope in Figure $7 \mathrm{~A}$. 

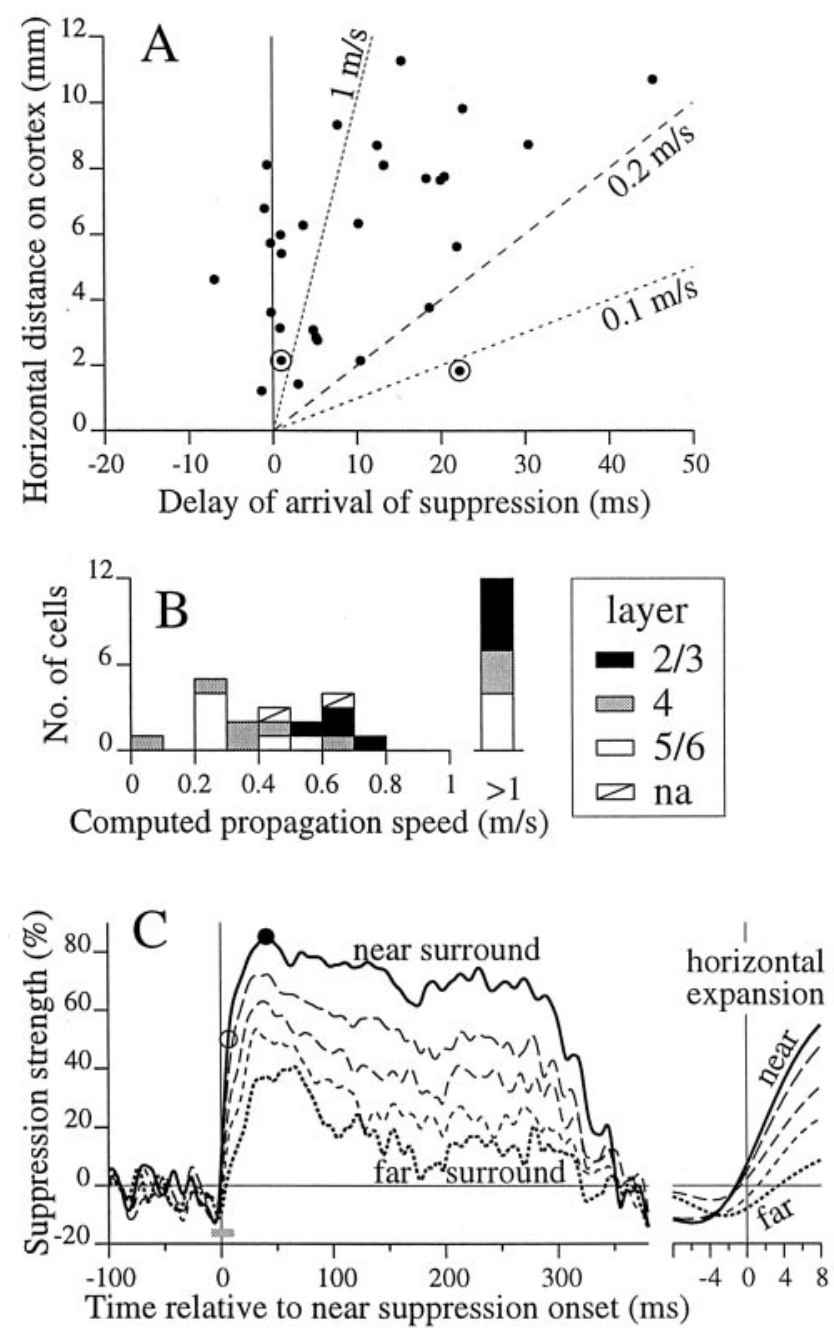

Figure 7. Dependence of latency and time course of surround suppression on surround distance and its implications for propagation velocity. $A$, The $x$-axis plots the latency for far suppression minus that for near suppression, $\Delta t$; see Results). The $y$-axis plots the cortical distance associated with the change in radius between the near and far surrounds ( $\Delta x$; see Results). Points show data for 31 neurons. The dashed lines mark propagation speeds of $1,0.1$, and $0.2 \mathrm{~m} / \mathrm{sec}$. The vertical line indicates zero delay, i.e., instantaneous propagation. $B$, The propagation speed for suppression implied by the data in $A$ was computed for each cell by dividing the cortical distance by the delay time. The bar at the right marked $>1$ represents all cells that had propagation speeds of $>1 \mathrm{~m} / \mathrm{sec}$ and includes the six cells that had $\Delta t$ of $<0$ in $A$. The shading indicates the estimated laminar location (see Materials and Methods) of the cells within the cortex. Histological reconstruction was not available for two cells (diagonal lines). C, Average suppression strength is plotted as a function of time. For each cell, suppression versus time was computed for each of five surrounds by subtracting the suppressed response from the response to the CRF alone. This difference was expressed as a percentage of the unsuppressed (CRF-alone) response. All curves for a cell were aligned to the latency of that cell for near suppression. The average onset latency for near suppression was $46 \mathrm{msec}$. The solid line shows the average near surround curve for all cells. The open and filled circles mark the time of $50 \%$ suppression (at $7 \mathrm{msec}$ ) and the time of peak suppression (85\% at $41 \mathrm{msec}$ ) on the near surround curve. Lines with shorter dashes show averages for more distant surrounds. The average suppression curve for the far surround (line with shortest dashes) has a significant transient component that exceeds $40 \%$ suppression from $\sim 30$ to $70 \mathrm{msec}$. Suppression from 200 to 300 msec was weak for far surround stimuli. The region around $t=0$ (main plot, gray bar) is expanded at the right.

If horizontal axonal projections mediate surround suppression, we would expect our data to reflect their conduction speed. Several studies suggest that propagation speed in such thin, unmyelinated fibers is $\sim 0.1-0.2 \mathrm{~m} / \mathrm{sec}$ (Grinvald et al., 1994; Bringuier et al., 1999; Girard et al., 2001; Slovin et al., 2002). Dashed lines mark these speeds in Figure 7A. Almost all of our data fall above these lines, suggesting that iso-orientation surround suppression must be carried by a mechanism that does not rely on the slow propagation associated with long-range horizontal connections. The propagation speed associated with each point is plotted in a frequency histogram in Figure $7 B$, where shading indicates the cortical layer assigned to each cell from histological reconstruction of the recording sites. Points near and to the left of the $y$-axis (Fig. 7A) account for the 12 cells having speeds of $>1$ $\mathrm{m} / \mathrm{sec}$ (Fig. $7 B$ ). These points, distributed widely throughout the depth of the cortex, imply an unprecedented speed for horizontal propagation. A more tenable hypothesis, considered in Discussion, involves feedback from cells with large receptive fields.

It might be argued that we overestimated propagation speed because some cells driving the surround suppression had RFs that overlapped the inner edge of the surround stimulus and hence were closer to the center of the CRF. However, such cells probably did not contribute to the short latency of suppression. Rossi et al. (2001) showed that neuronal response latency increased precipitously as stimuli were withdrawn from the center of the CRF. Their Figure 9 shows that a stimulus receding by $\sim 0.5^{\circ}$ at a position $0.5^{\circ}$ from the CRF center leads to a delay of $10 \mathrm{msec}$. This is consistent with delays on the order of $10 \mathrm{msec} /{ }^{\circ}$ shown in intracellular recordings in V1 by Bringuier et al. (1999). Thus, signals from any cell closer than one centered at the inner edge of the surround stimulus would be delayed. Furthermore, the weakening of suppression with distance should lead us to overestimate its latency by several milliseconds (see Materials and Methods). These factors suggest that our estimates of effective propagation speed are not inflated.

The most striking change that we observed for more distant surrounds was neither the change in latency nor the expected weakening of suppression. Rather, the examples in Figure 6 show that responses to far surround stimuli were dominated by a transient component that was less evident for near surrounds. Most cells (22 of 31) showed clear signs that the sustained component of suppression weakened more than the initial transient component for far surrounds, but several others (4 of 31) had strictly sustained suppression that decreased evenly in time for surround stimuli lying farther from the CRF. To quantify this trend across the database, we computed for each cell the average suppression as a function of time for the response to surrounds at each of five successive distances. All resulting curves for a given cell were shifted by the latency of near suppression onset for that cell, making $t=0$ the time of near suppression onset. The time-shifted curves for near suppression were averaged across all cells to produce the near surround average in Figure $7 C$ (solid line). This plot shows that suppression peaked at $85 \%$ at $t=41 \mathrm{msec}$ (filled circle). The conventional, steady-state method of estimating suppression from the size tuning curve yielded a significantly smaller value of 58\% (SEM, 5\%, computed as the ratio of response for the optimal size to the response asymptote for large stimuli; Cavanaugh et al., 2002). The average of all curves for far surround stimuli is also shown (line with shortest dashes). The average far surround curve peaks at $\sim 45 \%$ suppression around 30-70 msec. Its peak width partly reflects variability in the timing of narrow transients for individual cells. In the second half of the $300 \mathrm{msec}$ test period, the far surround curve drops to around 15\% suppression, less than half of its peak value. By comparison, the near surround curve is less transient, decreasing by only a small fraction of its peak value. Average curves for the three successive mid surrounds are also plotted, and these show a systematic progression from near to far in which suppression in the latter half of the 
300 msec period weakens with distance more than does the suppression in the early part of the period.

It is worth emphasizing that curves for each cell in Figure $7 C$ were aligned to its time of near-suppression onset, yet the population averages all show rapidly increasing suppression starting at time 0 (or a few milliseconds thereafter for the far surround curve). This reinforces the observation made above that, for a substantial fraction of cells, there was very little change in timing of the onset of suppression with distance from the CRF.

Finally, an important aspect of our study is that we tested only the part of the surround that did not significantly overlap the CRF. For each cell, we attempted to move the inner diameter of our surround stimulus closer to the CRF but found that the surround stimulus then elicited a CRF response that obscured the time course of suppression. On average, our surround stimuli were separated from the CRF stimulus by $28 \%$ of the CRF diameter Therefore, we cannot say how the timing of suppression depends on distance within the very near surround. However, we used high-contrast stimuli, which minimize the apparent size of the CRF (Kapadia et al., 1999; Sceniak et al., 1999; Cavanaugh et al., 2002), and therefore have tested as close to the CRF as our methods allow.

\section{Discussion}

We will first briefly discuss two basic novel findings about the time course of surround suppression: that, on average, more strongly suppressed cells were suppressed sooner and that suppression had a transient component that was prominent for surround stimuli lying farther from the CRF. We will then discuss the answers to the two questions that motivated this study. First, is the asymmetry in the timing of CRF response onset and offset reflected in the timing of surround suppression? Second, how does the timing of suppression depend on the distance of the surround stimulus from the CRF? The answers were not the ones anticipated for the simple circuit of Figure 1. We will argue that the lack of onset-offset asymmetry for surround suppression may be accounted for in terms of the dynamics of signals at the inhibitory relay, whereas the effectively rapid propagation of signals from distant surround stimuli constrains the circuitry carrying the excitatory responses that drive the inhibition.

\section{Delay of signals from the surround relative to those from the CRF}

The delay of surround suppression with respect to CRF excitation has been reported previously to range from 15 to $60 \mathrm{msec}$ (Knierim and Van Essen, 1992; Lamme, 1995; Zipser et al., 1996; Lee et al., 1998; Lamme et al., 1999; Nothdurft et al., 1999, 2000; Hupé et al., 2001b). Our measurements revealed that this delay varies systematically across cells: the delay was on average $30 \mathrm{msec}$ longer for weakly suppressed cells compared with strongly suppressed cells. In strongly suppressed cells, suppression often arrived earlier than CRF excitation. It is possible that variation in the sizing of surrounds caused some to be near, giving strong, early suppression, and others to be far, giving weak, late suppression. It is also possible that our method of measuring timing was biased to find that weaker suppression came later. However, our results on the distance dependence of suppression argue strongly against these explanations. In those experiments, suppression became substantially weaker as we moved the surround great distances from the CRF, yet in only 2 of 31 cells did this yield a delay of $>25 \mathrm{msec}$. Variations in surround placement in our onsetoffset experiments could be only a small fraction of distances used in the distance dependence experiments. They cannot account for the 30 msec change in delay with suppression strength. Therefore, we conclude that the relationship between suppression strength and timing reflects a property of the cortex. Perhaps iso-orientation suppression is carried by multiple pathways, some being more direct, thus faster, and more powerful than others.

\section{Onset and transience of surround suppression}

Iso-orientation surround suppression achieved its maximum strength on average within $50 \mathrm{msec}$ from its onset (Fig. 7C). Thus, despite its modulatory nature, surround suppression can act as suddenly as the direct-driving CRF signals. In addition to its abrupt onset, suppression often had a strong transient component that was revealed as surround stimuli were placed farther from the CRF. We had expected suppression from distant surrounds to be weaker (Jones, 1970; Hess et al., 1975; Nothdurft et al., 1999; Levitt and Lund, 2002), but past studies of the time course of surround signals did not mention a transient component (Knierim and Van Essen, 1992; Lamme, 1995; Zipser et al., 1996; Lee et al., 1998; Lamme et al., 1999; Nothdurft et al., 1999, 2000). However, those studies used different stimuli and focused on population-averaged responses. Further characterization of the set of stimulus conditions required to elicit transient suppression is necessary before we can understand its functional significance.

\section{There is no onset delay for surround suppression}

We previously reported that neurons in the visual system have an onset-offset asymmetry in their CRF-driven responses (Bair et al., 2002). This holds for the CRF-driven responses here: CRF onset latencies were on average $17 \mathrm{msec}$ longer than offset latencies. In the circuit of Figure 1, the neurons that generate the surround signal should also have the onset delay because their CRFs experience orientation changes similar to those in the center. If the inhibitory relay retains the timing of the surround signal, then the onset of suppression should be delayed because it is driven by delayed responses to preferred orientation in the surround. Contrary to this prediction, we found no timing difference between the onset and release of suppression. Perhaps we observed no timing asymmetry for suppression because the orientation-tuned signal that drives suppression has no asymmetry. This might occur if suppression originated from a subset of cells that lacked the onset-offset asymmetry; however, very few cells fit this criterion.

Alternatively, it is possible that the onset delay exists in the signal that drives suppression but is canceled by the inhibitory relay. How this could happen is depicted by the four traces in Figure $8 \mathrm{~A}$. Trace F plots the level of activity in the CRF-driven feedforward inputs to the cells (S) that supply the surround signal. The $\mathrm{S}$ cells are activated (high state, trace $\mathrm{S}$ ) by $\mathrm{F}$ after a delay (light gray band) that corresponds to their CRF onset delay (17 msec on average). Trace I shows that the response of the inhibitory relay follows its excitatory input from $S$ with little delay. This is supported by reports that inhibitory neurons are activated very rapidly and can retain the temporal structure of their inputs ( $\mathrm{Si}$ mons, 1978; Swadlow, 1989; Connors and Gutnick, 1990; Tama's et al., 1997). The target neuron (T) receives the suppression from I and suppresses rapidly after I activates. This sequence of events defines the period marked suppression (Fig. $8 \mathrm{~A}$, bottom left). If either the inhibitory neuron or the target neuron had not followed its inputs rapidly, suppression onset would have occurred even later than shown. Now, consider the timing of the release of suppression. If the response of T recovered rapidly (dashed line) 


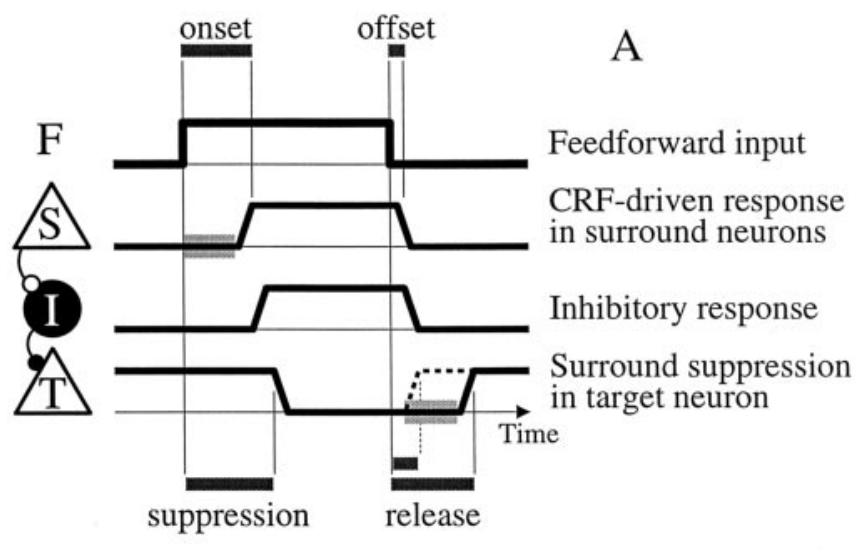

B

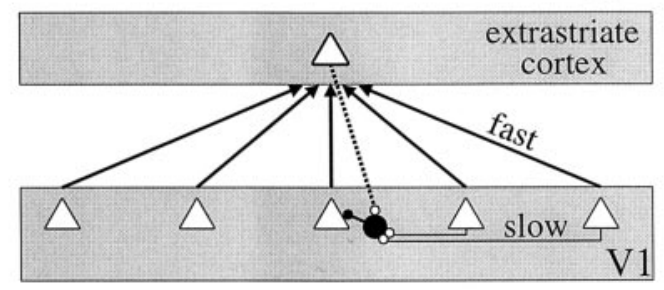

Figure 8. Refinements to the model shown in Figure 1 to account for the timing of the surround response. $A$, This hypothetical timing diagram can account for the presence of the onset delay for the CRF and its absence for the surround. The circuit (at the left) consists of a population of surround neurons (S), which inhibit a target neuron (T) via an inhibitory relay (I). The target and surround neurons have the same orientation preference. The four thick traces show the feedforward input $(F)$ and responses versus time for three elements in the circuit. Active and inactive states are shown by high and low values, respectively. The (RF input to the target neuron ( $\mathrm{T}$ ) is assumed to be active (preferred stimulus) at all times (not plotted). The feedforward input driving the surround neurons is meant to indicate the timing of signals as they arrive in cortex; i.e., the subcortical delay is not represented. When the input is high, the surround stimulus is in the preferred configuration. The response of the surround neurons (S) has a delayed onset (light gray band), but response offset has little delay. Thus, the top traces (F, S) show the onset- offset asymmetry for neurons responding to their CRF stimulus (i.e., the bar marked offset is shorter than that marked onset). The response of the inhibitory relay (I) follows rapidly the signal from $S$. The response of the target neuron $(T)$ is initially high (its CRF stimulus is preferred; data not shown) and is then suppressed by the inhibitory signal. When inhibition from I turns off, the response of the target neuron should recover rapidly (dashed line). However, if the recovery of the response of T were delayed (light gray band), then the latency of its release from suppression (release bar) would be equal to its latency for suppression onset (suppression bar), consistent with our observations. B, Cells (triangles) in V1 (bottom gray box) project via fast axons (arrows) to a higher visual area (top gray box) where neurons have larger CRFs created by convergent input. If cells from the higher area project back (dotted line) directly or indirectly to local inhibitory neurons in V1 (black circle), then suppression from far regions of the surround could arrive on target cells in V1 with little additional delay compared with suppression from the near surround. This could explain the data points in Fig. $7 A$ that fall along the vertical line for zero delay.

when I inactivated, then the delay to release would be shorter than that to suppression onset (see short bar marked release and associated dashed lines). However, if the inhibition persisted through the period marked by the light gray band, then suppression and release latencies would be similar (solid lines, timing bars). In particular, if the effect of inhibition on the target cell persisted for a time equal to the onset delay for the CRF (17 msec on average), then the onset delay would be canceled for surround suppression. The required time is similar to the half-width of $\mathrm{GABA}_{\mathrm{A}}$ IPSPs, $16 \mathrm{msec}$, reported in the cat visual cortex (Tamás et al., 1997). In fact, it is possible that the CRF onset delay is itself the result of inhibition that persists after the removal of the orthogonal CRF stimulus. This inhibition might work by a mechanism similar to surround suppression and could use the same inhibitory neurons.

Thus, we hypothesize that the persistence of $\mathrm{GABA}_{\mathrm{A}}$ inhibition may be responsible for both the onset delay observed for the CRF and the lack of a similar delay for surround suppression. Such an asymmetry is consistent with the notion that inhibition has veto power over excitation.

\section{Suppression delay versus distance}

We measured the change in latency of suppression as the surround stimulus was moved farther from the CRF. For many cells, suppression was somewhat delayed for more distant surrounds, but for a substantial fraction of cells, there was very little delay, even for surround stimuli that were far from the CRF and evoked relatively weak suppression. The apparent propagation speed of suppression was $>1 \mathrm{~m} / \mathrm{sec}$ for $40 \%$ of cells, whereas only 1 of 31 cells yielded a speed $<0.2 \mathrm{~m} / \mathrm{sec}$. This effectively rapid propagation occurred in cells recorded in layers 2 and 3, layer 4, and deep layers. The most widely cited circuit for iso-orientation surround suppression involves long-range horizontal projections (Allman et al., 1985; Gilbert and Wiesel, 1989), which can extend for up to a $3.5-4.5 \mathrm{~mm}$ radius in layers 2 and 3 of macaque V1 (Angelucci et al., 2002; Stettler et al., 2002). Grinvald et al. (1994) (Slovin et al., 2002) described a wave of optically imaged activity that traveled at $0.09-0.25 \mathrm{~m} / \mathrm{sec}$ across V1 and suggested that it was related to surround suppression carried by long-range projections. Other studies reported that slowly conducting horizontal axons carry information at typically $0.1-0.2 \mathrm{~m} / \mathrm{sec}$ across the visual cortex (Bringuier et al., 1999; Girard et al., 2001). Our results strongly suggest that this form of slow propagation across the visual cortex cannot account for iso-orientation suppression. It follows that if long-range horizontal connections underlie slow propagation, they are insufficient to mediate the suppression that we have observed.

Can faster propagation within V1 explain our data? Higher conduction speeds have been found using electric shock. In cat cortical slices, Hirsch and Gilbert (1991) reported $0.3 \mathrm{~m} / \mathrm{sec}$ propagation in the upper layers over short distances $(\sim 1 \mathrm{~mm})$. Girard et al. (2001) reported $0.3 \mathrm{~m} / \mathrm{sec}$ in upper layers and 1.0 $\mathrm{m} / \mathrm{sec}$ in lower layers in monkeys across $<2 \mathrm{~mm}$; however, they stated that most horizontal fibers conduct slowly, $\sim 0.1 \mathrm{~m} / \mathrm{sec}$, in agreement with others (Grinvald et al., 1994; Bringuier et al., 1999; Slovin et al., 2002). Furthermore, recent studies showed that horizontal connections within $\mathrm{V} 1$ are limited in extent to 3.5-4.5 mm (Angelucci et al., 2002; Stettler et al., 2002), yet significant suppression came from $>4 \mathrm{~mm}$ away from the CRF center in 23 of 31 cells (median, $7.5 \mathrm{~mm}$; range, $2-15 \mathrm{~mm}$ ) for which we estimated propagation speed. This is consistent with earlier estimates that suppression in most cells extended to at least $7 \mathrm{~mm}$ in the cortex (Cavanaugh et al., 2002). In terms of RF size, Levitt and Lund (2002) reported a median diameter of $7.1^{\circ}$ for suppression in parafoveal recordings, which agrees with our median diameter of $6.6^{\circ}(n=21$, parafoveal cells). Synaptic relays could enhance the reach of horizontal connection, but each relay would add an integration time of 5-20 msec (Nowak and Bullier, 1997; Azouz and Gray, 1999). In summary, the documented speeds and distances for horizontal connections in V1 make them poor candidates for explaining our data.

Alternatively, rapid effective propagation of suppression could result from feedback from visual areas with large RFs, such as V2 or MT (Allman et al., 1985; Knierim and Van Essen, 1992; 
Lamme, 1995, Zipser et al., 1996; Nothdurft et al., 2000; Hupé et al., 2001a; Jones et al., 2001) (but see Hupé et al., 2001b). A feedback circuit is shown in Figure $8 B$, where fast axons (arrows) carry convergent inputs to create large CRFs in extrastriate cells (triangle, upper gray band). Feedback (dotted line) from such cells in an area remote from the foveal portion of V1 is an elegant geometrical way to achieve a surround latency that is mostly independent of distance. Area MT is well suited for this. Connections from V1 to MT conduct at $\sim 10 \mathrm{~m} / \mathrm{sec}$ (Movshon and Newsome, 1996; Nowak and Bullier, 1997), and cooling MT can influence surround-mediated responses in V1 (Hupé et al., 1998). Feedback from large RFs can also explain how suppression arises from beyond the reach of horizontal connections (Angelucci et al., 2002; Cavanaugh et al., 2002; Levitt and Lund, 2002). Therefore, on the basis of apparent propagation speed and horizontal spread, our data support feedback as a mechanism for iso-orientation surround suppression.

Several aspects of such circuitry remain to be worked out. For example, in the rat, monosynaptic inhibitory feedback to V1 is rare (McDonald and Burkhalter, 1993); feedback usually targets excitatory cells (Salin and Bullier, 1995; Johnson and Burkhalter, 1996; Shao and Burkhalter, 1996). Excitatory cells receiving feedback from MT should have large RFs. Large RFs exist in V1 but are encountered infrequently (Levitt and Lund, 2002). Testing the distance dependence of excitation in V1 cells with large RFs could help distinguish whether they arise from feedback or are built from slow intrinsic connections.

Finally, we consider how the feedback hypothesis fits with other results of our study. Our account of the lack of onset delay for the surround involved assumptions about the dynamics of signals at the inhibitory relay only, and it stands independent of the source of signals that drive the inhibition. However, the observation that some suppression comes early needs to be considered. If iso-orientation surround suppression is mediated solely by extrastriate feedback, then it is difficult to explain suppression that arrives as early as, or earlier than, CRF onset. Rather than resorting to the hypothesis that very early responses in V1 (earlier than any we measured) are relayed rapidly to extrastriate cortex and fed back fast enough to create early suppression, it is worth considering that there may be a second source of suppression that is local, strong, and fast in terms of absolute latency. It could bring rapid inhibition from nearby cells within $\mathrm{V} 1$, acting before excitatory CRF inputs reach threshold. This could account for several observations: the strong suppression that acts before CRF onset, the greater strength of suppression near the CRF (Levitt and Lund, 2002), and the modest increase in latency of suppression with distance that we observed for some cells. Also, variations in the influence of this suppression from cell to cell could account for the correlation between suppression strength and timing across cells, as discussed above. Such suppression could be carried by local and long-range inhibitory processes (Nelson and Frost, 1978; Salin and Prince, 1996) or over short distances by long-range horizontal connections onto local inhibitory neurons (Gilbert and Wiesel, 1983; Hirsch and Gilbert, 1991; McGuire et al., 1991). Having two suppression mechanisms that operate on different spatial scales is plausible. One mediated by feedback could subserve global interactions, e.g., between separate regions of an extended texture, and the other operating within V1 could subserve local processing, e.g., at the borders of an object or the boundary of a patch of texture (Das and Gilbert, 1999; Angelucci et al., 2002).

\section{References}

Albright TD, Stoner GR (2002) Contextual influences on visual processing. Annu Rev Neurosci 25:339-379.

Allman J, Miezin F, McGuinness E (1985) Stimulus specific responses from beyond the classical receptive field: neurophysiological mechanisms for local-global comparisons in visual neurons. Annu Rev Neurosci 8:407-430.

Anderson JS, Lampl I, Gillespie DC, Ferster D (2001) Membrane potential and conductance changes underlying length tuning of cells in cat primary visual cortex. J Neurosci 21:2104-2112.

Angelucci A, Levitt JB, Walton EJS, Hupé JM, Bullier J, Lund JS (2002) Circuits for local and global signal integration in primary visual cortex. J Neurosci 22:8633-8646.

Azouz R, Gray CM (1999) Cellular mechanisms contributing to response variability of cortical neurons in vivo. J Neurosci 19:2209-2223.

Bair W, Cavanaugh JR, Smith MA, Movshon JA (2002) The timing of response onset and offset in macaque visual neurons. J Neurosci 22:3189-3205.

Blakemore C, Tobin EA (1972) Lateral inhibition between orientation detectors in the cat's visual cortex. Exp Brain Res 15:439-440.

Born RT, Tootell RBH (1991) Single-unit and 2-deoxyglucose studies of side inhibition in macaque striate cortex. Proc Natl Acad Sci USA 88:7071-7075.

Bringuier V, Chavane F, Glaeser L, Frégnac Y (1999) Horizontal propagation of visual activity in the synaptic integration field of area 17 neurons. Science 283:695-699.

Cavanaugh JR, Bair W, Movshon JA (2002) Nature and interaction of signals from the receptive field center and surround in macaque V1 neurons. J Neurophysiol 88:2530-2546.

Connors BW, Gutnick MJ (1990) Intrinsic firing patterns of diverse neocortical neurons. Trends Neurosci 13:99-104.

Das A, Gilbert CD (1999) Topography of contextual modulations mediated by short-range interactions in primary visual cortex. Nature 399:655-661.

DeAngelis GC, Freeman RD, Ohzawa I (1994) Length and width tuning of neurons in the cat's primary visual cortex. J Neurophysiol 71:347-374.

De Valois RL, Thorell LG, Albrecht DG (1985) Periodicity of striate-cortexcell receptive fields. J Opt Soc Am A 2:1115-1123.

Dragoi V, Sur M (2000) Dynamic properties of recurrent inhibition in primary visual cortex: contrast and orientation dependence of contextual effects. J Neurophysiol 83:1019-1030.

Dreher B (1972) Hypercomplex cells in the cat's striate cortex. Invest Ophthalmol 11:355-356.

Fitzpatrick D (2000) Seeing beyond the receptive field in primary visual cortex. Curr Opin Neurobiol 10:438-443.

Fries W, Albus K, Creutzfeldt OD (1977) Effects of interacting visual patterns on single cell responses in cat's striate cortex. Vision Res 17:1001-1008.

Gilbert CD (1992) Horizontal integration and cortical dynamics. Neuron 9:1-13.

Gilbert CD, Wiesel TN (1983) Clustered intrinsic connections in cat visual cortex. J Neurosci 3:1116-1133.

Gilbert CD, Wiesel TN (1989) Columnar specificity of intrinsic horizontal and corticocortical connections in cat visual cortex. J Neurosci 9:2432-2442.

Gilbert CD, Wiesel TN (1990) The influence of contextual stimuli on the orientation selectivity of cells in primary visual cortex of the cat. Vision Res 30:1689-1701.

Girard P, JM Hupé, Bullier J (2001) Feedforward and feedback connections between areas V1 and V2 of the monkey have similar rapid conduction velocities. J Neurophysiol 85:1328-1331.

Grinvald A, Lieke EE, Frostig RD, Hildesheim R (1994) Cortical pointspread function and long-range lateral interactions revealed by real-time optical imaging of macaque monkey primary visual cortex. J Neurosci 14:2545-2568.

Hess R, Negishi K, Creutzfeldt O (1975) The horizontal spread of intracortical inhibition in the visual cortex. Exp Brain Res 22:415-419.

Hirsch JA, Gilbert CD (1991) Synaptic physiology and horizontal connections in the cat's visual cortex. J Neurosci 11:1800-1809.

Hubel DH, Wiesel TN (1968) Receptive fields and functional architecture of monkey striate cortex. J Physiol (Lond) 195:215-243.

Hupé JM, James AC, Payne BR, Lomber SG, Girard P, Bullier J (1998) Cor- 
tical feedback improves discrimination between figure and background by V1, V2 and V3 neurons. Nature 394:784-787.

Hupé J-M, James AC, Girard P, Lomber SG, Payne BR, Bullier J (2001a) Feedback connections act on the early part of the responses in monkey visual cortex. J Neurophysiol 85:134-145.

Hupé JM, James AC, Girard P, Bullier J (2001b) Response modulations by static texture surround in area $\mathrm{V} 1$ of the macaque monkey do not depend on feedback connections from V2. J Neurophysiol 85:146-163.

Jones BH (1970) Responses of single neurons in cat visual cortex to a simple and a more complex stimulus. Am J Physiol 218:1102-1107.

Jones HE, Grieve KL, Wang W, Sillito AM (2001) Surround suppression in primate V1. J Neurophysiol 86:2011-2028.

Johnson RR, Burkhalter A (1996) Microcircuitry of forward and feedback connections within rat visual cortex. J Comp Neurol 368:383-398.

Kapadia MK, Westheimer G, Gilbert CD (1999) Dynamics of spatial summation in primary visual cortex of alert monkeys. Proc Natl Acad Sci USA 96:12073-12078.

Kato H, Bishop PO, Orban GA (1978) Hypercomplex and simple/complex cell classifications in cat striate cortex. J Neurophysiol 41:1071-1095.

Knierim JJ, Van Essen DC (1992) Neuronal responses to static texture patterns in area V1 of the alert macaque monkey. J Neurophysiol 67:961-980.

Lamme VAF (1995) The neurophysiology of figure-ground segregation in primary visual cortex. J Neurosci 15:1605-1615.

Lamme VAF, Rodriguez-Rodriguez V, Spekreijse H (1999) Separate processing dynamics for texture elements, boundaries and surfaces in primary visual cortex of the macaque monkey. Cereb Cortex 9:406-413.

Lee TS, Mumford D, Romero R, Lamme VAF (1998) The role of the primary visual cortex in higher level vision. Vision Res 38:2429-2454.

Levitt JB, Lund JS (2002) The spatial extent over which neurons in macaque striate cortex pool visual signals. Vis Neurosci 19:439-452.

Levitt JB, Kiper DC, Movshon JA (1994) Receptive fields and functional architecture of macaque V2. J Neurophysiol 71:2517-2542.

Merrill EG, Ainsworth A (1972) Glass-coated platinum-plated tungsten microelectrode. Med Biol Eng 10:662-672.

McDonald CT, Burkhalter A (1993) Organization of long-range inhibitory connections within rat visual cortex. J Neurosci 13:768-781.

McGuire BA, Gilbert CD, Rivlin PK, Wiesel TN (1991) Targets of horizontal connections in macaque primary visual cortex. J Comp Neurol 305:370-392.

Mizobe K, Polat U, Pettet MW, Kasamatsu T (2001) Facilitation and suppression of single striate-cell activity by spatially discrete pattern stimuli presented beyond the receptive field. Vis Neurosci 18:377-391.

Movshon JA, Newsome WT (1996) Visual response properties of striate cortical neurons projecting to area MT in macaque monkeys. J Neurosci 16:7733-7741.

Nelson JI, Frost BJ (1978) Orientation-selective inhibition from beyond the classic visual receptive field. Brain Res 139:359-365.

Nothdurft H-C, Gallant JL, Van Essen DC (1999) Response modulation by texture surround in primate area V1: correlates of "popout" under anesthesia. Vis Neurosci 16:15-34.
Nothdurft H-C, Gallant JL, Van Essen DC (2000) Response profiles to texture border patterns in area V1. Vis Neurosci 17:421-436.

Nowak LG, Bullier J (1997) The timing of information transfer in the visual system. In: Cerebral cortex and extrastriate cortex in primates, Vol 12 (Rockland K, Kaas J, Peters A, eds), pp 205-241. New York: Plenum.

Rose D (1977) Responses of single units in cat visual cortex to moving bars of light as a function of bar length. J Physiol (Lond) 271:1-23.

Rossi AF, Desimone R, Ungerleider LG (2001) Contextual modulation in primary visual cortex of macaques. J Neurosci 21:1698-1709.

Salin PA, Bullier J (1995) Corticocortical connections in the visual system: structure and function. Physiol Rev 75:107-154.

Salin PA, Prince DA (1996) Electrophysiological mapping of GABAA receptor-mediated inhibition in adult rat somatosensory cortex. J Neurophysiol 75:1589-1600.

Sceniak MP, Ringach DL, Hawken MJ, Shapley R (1999) Contrast's effect on spatial summation by macaque V1 neurons. Nat Neurosci 2:733-739.

Shao Z, Burkhalter A (1996) Different balance of excitation and inhibition in forward and feedback circuits of rat visual cortex. J Neurosci 16:7353-7356.

Sillito AM, Grieve KL, Jones HE, Cudeiro J, Davis J (1995) Visual cortical mechanism detecting focal orientation discontinuities. Nature 378:492-496.

Simons DJ (1978) Response properties of vibrissa units in rat SI somatosensory neocortex. J Neurophysiol 41:798-820.

Slovin H, Arieli A, Hildesheim R, Grinvald A (2002) Long-term voltagesensitive dye imaging reveals cortical dynamics in behaving monkeys. J Neurophysiol 88:3421-3438.

Stettler DD, Das A, Bennett J, Gilbert CD (2002) Lateral connectivity and contextual interactions in macaque primary visual cortex. Neuron 36:739-750.

Swadlow HA (1989) Efferent neurons and suspected interneurons in S-1 vibrissa cortex of the awake rabbit: receptive fields and axonal properties. J Neurophysiol 62:288-308.

Tamás G, Buhl EH, Somogyi P (1997) Fast IPSPs elicited via multiple synaptic release sites by different types of GABAergic neurone in the cat visual cortex. J Physiol (Lond) 500:715-738.

Tootell RB, Switkes E, Silverman MS, Hamilton SL (1988) Functional anatomy of macaque striate cortex. II. Retinotopic organization. J Neurosci 8:1531-1568.

Toth LJ, Rao SC, Kim DS, Somers D, Sur M (1996) Subthreshold facilitation and suppression in primary visual cortex revealed by intrinsic signal imaging. Proc Natl Acad Sci USA 93:9869-9874.

Van Essen DC, Newsome WT, Maunsell JHR (1984) The visual field representation in striate cortex of the macaque monkey: asymmetries, anisotropies, and individual variability. Vision Res 24:429-448.

Vinje WE, Gallant JL (2000) Sparse coding and decorrelation in primary visual cortex during natural vision. Science 287:1273-1276.

Walker GA, Ohzawa I, Freeman RD (2000) Suppression outside the classical cortical receptive field. Vis Neurosci 17:369-379.

Zipser K, Lamme VAF, Schiller PH (1996) Contextual modulation in primary visual cortex. J Neurosci 16:7376-7389. 